\title{
BIOSPECTROSCOPY FOR PLANT AND CROP SCIENCE
}

\author{
Paul Skolik ${ }^{1}$, Martin C McAinsh ${ }^{1}$, Francis L Martin ${ }^{2}$ \\ ${ }^{1}$ Lancaster Environment Centre, Lancaster University, Lancaster LA1 4YQ, UK \\ ${ }^{2}$ School of Pharmacy and Biomedical Sciences, University of Central Lancashire, \\ Preston PR1 2HE, UK
}

\begin{abstract}
Plants as our most renewable natural resource are indispensable within earth's biosphere, especially for food security. Providing food security in a modern world requires an ever increasing understanding of how plants, and their products, respond to changes in the environment. In this respect, a combination of physical and chemical analytical methods can be used to study the structure and function of plants at the whole-plant, organ, tissue, cellular and biochemical levels. Vibrational spectroscopy in biology, sometimes known as biospectroscopy, encompasees a number of tehcniques, among them mid-infrared and Raman spectroscopy. These techniques are well established label-free, non-destructive, and environmentally friendly analytical methods that generate a spectral 'signature' of samples using mid-infrared radiation. The resultant wavenumber spectrum containing hundreds of variables as unique as a biochemical 'fingerprint' represents the biomolecules (proteins, lipids, carbohydrates, nucleic acids) present within a sample, which may serve as spectral 'biomarkers' for the discrimination of distinct as well as closely related biomaterials, for various applications. In plants, biospectroscopy has been used to characterize surface structures in intact plant tissues such as leaves and fruit, plant cuticles, and cell walls, as well as to study the effects of stress on plant species. Not only does this allow the effective discrimination and 'chemo-identification' of different plant structures, varieties and cultivars, it also permits chemical profiling of plant tissues for physiological applications such as plant health monitoring and disease detection. Technical advancements are starting to overcome the major limitations of biospectroscopy such as detection sensitivity, penetration/imaging depth, and computational analysis speed, expanding the application of biospectroscopy in the plant
\end{abstract}


and crop sciences. Vibrational spectra thereby serve as a basis for localization, identification, quantification of key compounds within plants, as well as to track dynamic processes for molecular level analytics and diagnostics. This provides development potential as sensors in automatic decision making platforms for areas including precision farming and the food production/supply chain. In this chapter we will discuss the application of biospectroscopy to study plant and crop biology and consider the potential for advancements to make biospectroscopy a more prominent technology for fundamental plant research and applied crop science as part of solutions to agricultural challenges both now and in the future.

Key words: Biochemical fingerprint; Crop biology; Diagnostic framework; Mid-infrared spectroscopy; Multivariate analysis; Raman spectroscopy

\section{INTRODUCTION}

Plants as primary producers constitute one of the most important natural resources on earth, contributing to food security, medicine, energy, and providing a source of a tremendous amount of materials and compounds. Yet successful cultivation of plants and distribution of their products, specifically for food security remains a key challenge in the $21^{\text {st }}$ century. While malnutrition continues to plague up to one in three humans (IFPRI 2017) environmental and social issues such as climate change, declining natural resources, harmful commercial chemicals, and population growth, confound food production. Current models of population rise predict the global total to reach between approximately nine and 12 billion people by the end of the century (Gerland et al 2014). The predicted global population rise merits increases between 100-110\% for crop production by the year 2050, prompting and increase in agricultural output by approximately $60-110 \%$ by the same year (Ray et al 2013). However, production of at least several major crop species including maize, corn, soybeans, potatoes, are not increasing as necessary to meet predicted future demands, and it is likely that global food demand will not be met throughout this century, especially in developing nations (Table 1) (Godfray et al 2010; Ray et al 2013; Mahlein et al 2016). Besides direct economic value, crop losses additionally contribute to subsequent losses for, or impacts on, 
consumers, health systems, global resources, and the environment (Savary et al 2012). Not only does the insufficient production of staple crops contribute to the problem of attaining food security, waste is also a major factor throughout the food production and food supply chains (Godfray et al 2010). Pre- and post-harvest crop loss contributes to the $40 \%$ of all food lost to waste in both developed and developing nations (Godfray et al 2010). This level of loss and waste throughout the food system seems removed from a precision and sustainable agricultural framework.

Table 1: Predicted annual crop production and deficits until 2050 in major crops of Maize, Rice, Wheat, and Soybean (Adapted from Ray et al 2013).

\begin{tabular}{l|c|c} 
Crop & Estimated Annual Production (\%) & Estimated Annual Deficit (\%) \\
\hline Maize & 67 & 33 \\
Rice & 42 & 58 \\
Wheat & 38 & 62 \\
Soybean & 55 & 45
\end{tabular}

Plant disease is one of the major threats to food security and crop cultivation. Unfavourable environmental conditions, pests, and pathogens can destroy whole crops or reduce the quality of plant products in both pre and post-harvest situations (Scott and Strange 2005). Non-biological factors negatively affecting plants and crops induce abiotic stress, while biological threats illicit biotic stress responses, which if overcome lead to plant disease (Bostock et al 2014). Biotic and abiotic stress, alone or in combination, negatively influence plant physiology, harming growth and development, leading to reduced crop yields (Suzuki et al 2014). Especially stress combinations can have synergistic effects, leading to more crop loss than the sum of individual stresses (Figure 1) (Suzuki et al 2014). This is especially true with combinations of abiotic stresses and abiotic-biotic stress combinations (Suzuki et al 2014). Additionally, reduced crop yield (losses) due to pests and pathogens remain significant determinants in 
effectively increasing horticultural production (Oerke and Dehne 2004). Pest and pathogen-induced disease can reduce global annual yield by $40 \%$ for major agricultural crops (Oerke 2006), while similarly, post-harvest, pathogens can infect produce during transport, storage, and household consumption leading to regular losses over 35\% (Oerke 2006; Godfray et al 2010). Such levels of crop loss and food waste suggest that current methods of crop protection and post-harvest handling of horticultural goods are still inadequate under a modern precision farming framework. Part of the reason is the lack of commercial analytical and diagnostic tools to detect threats to plants and crops throughout the food production and food supply chains (Mahlein 2016).

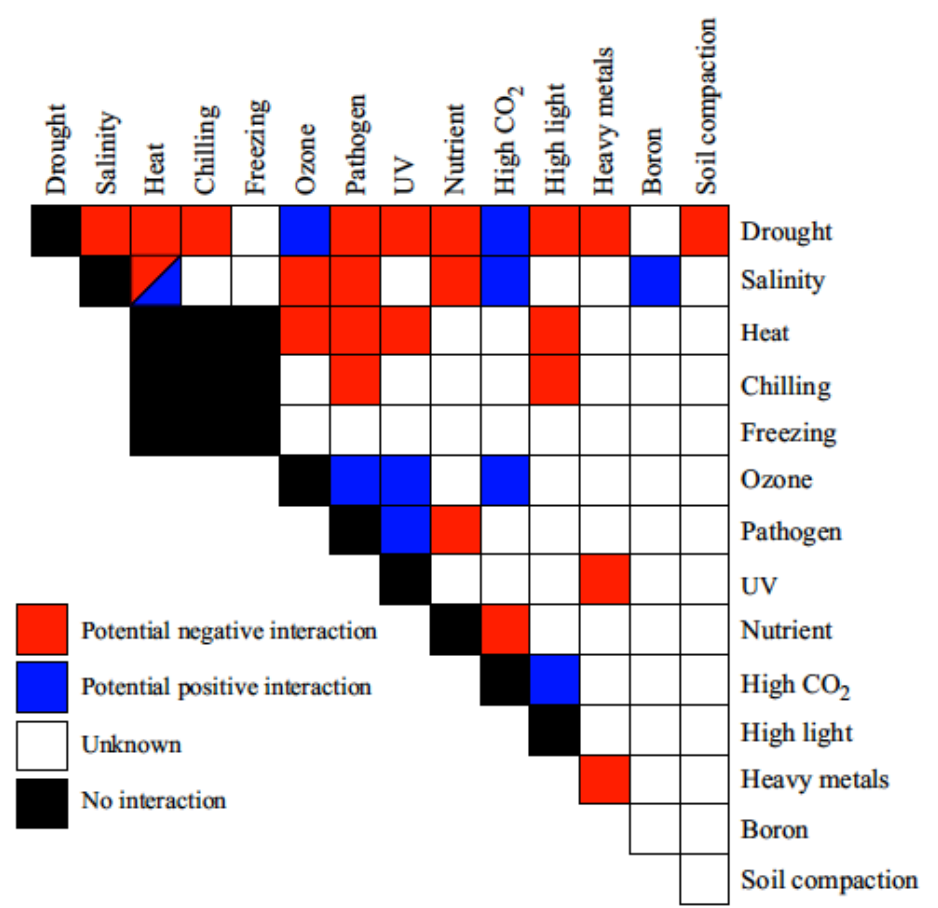

Figure 1: Stress interaction matrix showing stress combinations (abiotic/biotic) including synergistic (positive) and antagonistic (negative) interactions among others (Adapted from Suzuki et al 2014).

The complexity of plants and their interactions with the environment, including biotic and abiotic factors, are therefore prominent research areas requiring analytical and diagnostic tools for fundamental plant biology and crop science, in efforts to develop solutions to horticultural losses. An increased physiological and molecular level understanding of how plants respond to changes in the environment (biotic and abiotic 
factors) and how these conditions influence the composition of valuable plant substances for human use would therefore be beneficial for making improvements in horticulture. For this, a combination of physical and chemical analytical methods are available to study static and dynamic structure-function relationships of plants at the whole-plant, organ, tissue, cellular and biochemical level. These include both destructive and nondestructive methods, such as nucleic acid based or traditional molecular techniques that are destructive, as well as proximal and distal optical sensors such as spectroscopy, remote sensing, and volatile organic compound (VOC) analysis, which are possible nondestructively (Martinelli et al 2014). Combined, these sensors based methods share common goals aimed at the following priorities: plant health monitoring and presymptomatic disease detection; identification of different plant varieties and cultivars including plants naturally resistant to stress for genotyping/phenotyping and taxonomic classification purposes; and increasing mechanistic insight into plant physiology and disease (Martinelli et al 2014; Mahlein 2016). Non-destructive optical sensor technologies have gained popularity due to the possibility to study plants in their natural context, while gaining biologically important information relevant to fundamental plant research and applied crop science (Mahlein 2016). Many of these technologies can therefore contribute simultaneously to lab-based as well as industry-applied efforts towards crop protection. To this end, various non-destructive optical sensors have shown promise, in the context of crop loss and food waste, by contributing knowledge to both fundamental plant research and applied crop sciences (Sankaran et al 2010; Martinelli et al 2014; Mahlein 2016).

Mid-infrared (MIR) vibrational spectroscopy of biological materials has developed into a versatile tool for fundamental plant research, with development potential as a sensor for applied crop sciences. Vibrational spectroscopy in biology known as biospectroscopy, encompasses well-established label-free, non-destructive, and environmentally friendly analytical methods that generate wavenumber spectra of samples using MIR radiation. A wavenumber spectrum contains hundreds of variables as unique as a biochemical 'fingerprint', and reflects the biomolecules (proteins, lipids, carbohydrates, and nucleic acids) present within a sample (Baker et al 2014). Changes in specific wavenumber variables of the IR spectrum may serve as spectral 'biomarkers' for 
the discrimination of distinct as well as closely related biomaterials, for various applications (Martin et al 2010). Among the most common biospectroscopy methods are MIR and Raman spectroscopy. General applications of biospectroscopy include the study of biomolecules in vivo, cell variability and identification of particular phenotypes, and measuring biochemical processes on the cellular and sub-cellular level both spatially and temporally (Quaroni and Zlateva 2011). Measuring concentration gradients, the orientation of biomolecules in living cells, distinguishing cellular phenotypes, detection of specific metabolites or compounds, as well as measuring dynamic changes in biomolecule abundance and distribution are routine applications of biospectroscopy (Martin et al 2010; Quaroni and Zlateva 2011). Plant and crop science specific application highlights of biospectroscopy include the characterization of many valuable plant substances such as primary and secondary metabolites; investigation of plant surface structures including external barriers like the cell wall and cuticle; chemoidentification plant varieties and cultivars; as well as measuring effects of major abiotic and biotic stress conditions (Schulz and Baranska 2007; Heredia-Guerrero et al. 2014; Largo-Gosens et al 2014; Zimmermann et al 2015; Ord et al 2016). This includes studies on various plant parts including samples from leaves, fruit, roots, stems, and pollen, highlighting its applicability to various plant systems (Stuart et al 1997; Ribeiro da Luz 2006; Zimmermann et al 2015; Fu et al 2016 White et al 2016). Yet because most biospectroscopy experiments use destructive sample preparation compromises both the physiological relevance, as well as non-destructive benefits of these methods, restricting biospectroscopy primarily to the laboratory and to industry applications relying on the more traditional uses of IR spectroscopy to homogenous bulk sample analysis. In order to develop biospectroscopy further, specifically towards being an applied sensor for industry and laboratory alike, more non-destructive in vivo investigations using biospectroscopy are needed (Butler et al 2015). While the number of in vivo studies of biospectroscopy are to date limited primarily by technical limitations, sufficient proof-ofconcept exists to warrant further evaluation for intact plant and crop analysis without destructive sample preparation as a prerequisite. To this end, recent developments show that spectral alterations of measurements taken in vivo within intact plants and crops can be physiologically representative (Trebolazabala et al 2013; Butler et al 2015; Fu et al 
2016). Further, semi and fully portable MIR and Raman spectrometers are available for potential field use. A number of recent studies have investigated semi-portable and miniature biospectroscopy equipment, primarily Raman, for in vivo measurements in tomato fruit (Trebolazabala et al 2013; Fu et al 2016). Applications of biospectroscopy to date in the laboratory and industry, combined with recent developments and the increasing availability of portable biospectroscopy systems, suggest that these methods may become rapidly adapted to serve as sensors for field applications in various pre and post-harvest scenarios. Because biospectroscopy is inherently interdisciplinary, research collaborations, knowledge transfer, together with technical advancements and the evaluation of fully portable biospectroscopy equipment, will contribute to biospectroscopy sensor development, facilitating better crop protection and reducing food waste in future food production/supply. Herein, we summarize the main concepts of biospectroscopy including sample preparation, spectral acquisition, and data analysis of MIR and Raman spectroscopy. Biospectroscopy applications to valuable plant substances, select surface structures such as the cuticle and cell wall, identification of varieties and cultivars, as well as plant-environment interactions, including abiotic and biotic stress, are reviewed. Analysis of crop plants, intact specimens (in vivo or in situ), as well as the use of more portable systems is highlighted. We also outline select challenges and limitations specifically relevant to the transition from lab instrument to field sensor. Further, we briefly suggest novel directions for biospectroscopy in plant and crop sciences.

\section{BIOSPECTROSCOPY}

Biospectroscopy refers to a collection of techniques including, but not limited to, MIR and Raman spectroscopy for applications in biology. These techniques rely on the interaction between infrared (IR) radiation and the functional groups present in biomolecules, to generate a unique IR spectrum over the range of wavelengths from 2.5$25 \mu \mathrm{m}$, converted to energy units in wavenumbers $\left(4000-400 \mathrm{~cm}^{-1}\right)$. Energy in the IR range causes molecular excitation, vibration, and rotation of molecules within a biological sample. Functional groups present in biomolecules such as proteins, lipids, carbohydrates, and nucleic acids, characteristically interact with IR radiation (Baker et al. 2014). Biochemically complex samples such as those from biological materials therefore 
produce information rich and highly characteristic spectra for multi component analysis (Moros et al 2010). The highly characteristic and unique IR spectra also referred to as samples biological 'fingerprint' spectrum or IR 'signature' are exceptionally useful to distinguish between remarkably similar samples based on minute biochemical alterations. IR spectra therefore provide the basis for classification and characterization, as well as tracking both large and small biochemical changes over time (Quaroni and Zlateva 2011). Distinct light-matter interactions are measured by MIR and Raman spectroscopy over the same energy range (4000-400 $\left.\mathrm{cm}^{-1}\right)$, producing unique but complementary information, and when used in combination provide a more detailed analysis of the sample. Various sample modes allow the probing of different sample areas covering spatial resolution from the nanometre scale up to spectra representing areas covering square millimetres (Kazarian and Chan 2013), which permits the interrogation of biological systems at various levels of biological organization.

\section{Mid-Infrared Spectroscopy}

MIR spectroscopy relies on light absorption. Incident IR light upon a sample causes biochemical bonds to vibrate. Vibrational modes of molecule thereby cause specific amounts of energy from the incident IR beam to be absorbed, reducing the intensity of the subsequently detected IR beam. The difference in energy between incident and detected IR radiation produces a complex interferogram, which is de-convoluted using a FT operator (Stuart 2004). This separates the individual wavelengths of the measured IR range into component wavelengths producing a wavenumber spectrum. MIR spectroscopy, in contrast to Raman spectroscopy, relies and a dipole present only in diatomic, or more complex molecules, which is not a limitation within biological materials.

\section{Raman Spectroscopy}

Raman spectroscopy relies on molecular excitation by way of polarization and subsequent light scattering. Incident photons from the IR laser source interact with a molecular configuration resulting in elastic or inelastic light scattering. Elastic light scattering, known as Rayleigh scattering, predominates resulting in no net energy transfer between incident IR radiation and sample molecules, providing no information and 
therefore filtered out (Smith and Dent 2013). Alternatively, a net energy decrease or increase in the scattered IR light, resulting in inelastic light scattering known as StokesRaman and anti-Stokes-Raman scattering respectively (Andrews 2014). Fluorescence can interfere with the detector signal due to its occurrence at similar energy transitions as those detected by Raman spectroscopy. Raman scattering, measured over the same energy range as MIR spectroscopy (4000-400 $\mathrm{cm}^{-1}$ ) but each measuring distinct lightmatter interaction phenomena, make these two methods complementary. Various forms of Raman spectroscopy make use of these phenomena in different ways, expanding the application potential of these techniques to biological analysis (Butler et al 2016).

For a detailed account of MIR and Raman spectroscopy theory, which is out of the context of this discussion, more information can be found in the literature (Stuart 2004; Smith and Dent 2013; Andrews 2014; Baker et al 2016a). Because of its versatility, it is important to make the appropriate choices at each stage of the biospectroscopy process to meet the intended research aims and objectives. To aid experimental design and provide an overview, the biospectroscopy method may be divided into three component parts including sample preparation, spectral acquisition, and computational analysis (Kelly et al 2011b; Trevisan et al 2012). A number of protocols have become available for new users with guidance on sample preparation, spectral acquisition, and computational analysis for a number of samples. These protocols exist for both MIR and Raman analysis of biological materials (Gierlinger et al 2012; Baker et al 2014; Butler et al 2016).

\section{Sample Preparation}

Vibrational spectroscopy can measure virtually any type of organic material; however, sample preparation may considerably alter the vibrational spectrum compared to the sample in its native state. Many types of sample preparation are employed within the plant laboratory including physical and or chemical modifications of the sample. Concerning plants, common sample preparation may include cutting, drying, grinding, homogenization, fixation, fractionation, purification etc., most of which influence the IR spectrum to some degree. Benefits of sample preparation include the ability to take complex biological systems including plant cells and tissues, and separate them into less 
complex constituents for a more precise characterization of individual substances. Several studies have investigated select effects of sample preparation on IR spectra under specific conditions (Bureau et al 2012; Zohdi et al 2015). Nevertheless, extensive sample preparation consumes time and resources while altering the native architecture of biological tissues, which may limit or remove any physiological context of the resultant data, and thus there is a general desire to perform analysis in vivo where possible. Despite the ability to measure a vast array of sample types, the use of biospectroscopy for in vivo measurements has been surprisingly limited, especially in the plant and crop sciences. Nonetheless, biospectroscopy is being applied to an increasing amount of in vivo systems and a number of studies have demonstrated that in vivo analysis of whole cells and tissues is readily achieved (Heraud et al 2005; Trebolazabala et al 2013; Butler et al 2015; Fu et al 2016). These studies demonstrate that analysis of both processed and native samples is possible, and while different types of sample preparation precede most biospectroscopy studies to date, the continued development of in vivo analysis is favourable for the nondestructive measurements of physiologically active plants and crops (Butler et al 2015). Additionally, the analysis of plant cells and tissues in vivo requires practically no sample preparation, while having the benefit of being physiologically representative under native conditions, which contributes to faster spectral acquisition, increasing the relevance for future industry applications.

\section{Spectral Acquisition}

Instrument choices influence the area of interrogation, sensitivity, spatial resolution, and acquisition speed of measurements in biospectroscopy. Three main sampling modes are available for biospectroscopy; these are transmission, reflectance and attenuated total reflection (ATR) spectroscopy (Smith 2011). These sampling modes are applicable to both MIR and Raman spectroscopy. For MIR in transmission mode, light passes through the sample and due to the energy of MIR, is generally limited to thicknesses up to 20 micrometres (Smith 2011). Furthermore, because most intact biological samples are thicker than this limit, sample preparation is necessary, although this has beneficial effects on the quality of resultant spectra (Butler et al 2017). Thus for in vivo analysis, transmission mode may be limited to specific samples suitable to this acquisition mode. 
In contrast, Raman transmission spectroscopy has a sample thickness capacity in the range of 30 millimetres, expanding this sampling mode to thicker plant tissues (Butler et al 2016). This is because the laser sources used for Raman analysis generally have higher energy than regular MIR excitation sources and thus penetrate deeper into biological samples. The same is true for traditional Raman scattering, where laser light penetration into plant tissues is in the range of several hundred micrometres (Butler et al 2015). For Raman spectroscopy, additional light-matter phenomena may be exploited through a number of adaptions of the technique including surface enhanced Raman spectroscopy (SERS) and stimulated Raman scattering (SRS) applied to plant samples (Littlejohn et al 2015; Butler et al 2016; Zhang et al 2017). Although not common outside specialized applications, MIR spectroscopy utilizing synchrotron radiation from specialized particle accelerators can provide an exceptionally bright excitation source for spectral acquisition in several specialized adaptions of biospectroscopy to plants and pathogens (Kaminskyj et al 2008; Holman et al 2010; Butler et al 2017).

Sensitivity and selectivity of MIR and Raman spectroscopy are dependent on method and instrument choice. Sensitivity is the detection limit for a particular chromophore, as determined by its absorption relative to background noise, while the selectivity is the capability of detecting specific chromophores within a mixture (Quaroni and Zlateva 2011). Sensitivity and specificity parameters may be optimized depending on the aim of the experiment, and are important to determine if biospectroscopy techniques are suitable for the study, compared to other available analytical methods.

Spatial resolution covers macroscopic (macro measurements) areas down to nanometre level resolution (micro measurements) depending on the method used (Kazarian and Chan 2013; Baker et al 2016a). While a significant amount of effort is put into improving spatial resolution on the micro and nanometre levels, macroscopic measurements covering several square millimetres or centimetres may be more appropriate for measuring physiological processes in whole plant organs, especially for rapid routine analysis. Although micro-measurements permit the imaging or mapping of specific regions at cellular and sub-cellular resolution.

Spectral resolution refers to the number of variables generated in a spectroscopic 
measurement. A spectral resolution of $4 \mathrm{~cm}^{-1}$ would generate roughly twice as many wavenumber variables in the spectrum as a spectral resolution of $8 \mathrm{~cm}^{-1}$, thus increasing scan time significantly (Quaroni and Zlateva 2011). Depending on instrument choice, and measurement area, spectral acquisition time will vary significantly. It is possible to choose sampling modes, which allow the optimization of measurement area, penetration depth into the sample surface, as well as spatial and spectral resolution, all of which have an impact on spectral quality and acquisition speed (Quaroni and Zlateva 2011).

\section{Computational Analysis}

Extracting wavenumber variables from biological samples to serve as 'spectral biomarkers' related to a specific effect or treatment requires computational analysis in order to answer biologically relevant questions. IR and Raman spectra contain hundreds of variables with both qualitative and quantitative attributes for analysis (Baker et al 2014). In general, extracting biological information from vibrational spectroscopy data falls into two main categories consisting of exploratory and diagnostic frameworks (Trevisan et al 2012). The exploratory framework focuses on data visualization and direct comparisons of spectral groups for primarily qualitative analysis and characterization of spectral features (Trevisan et al 2012). A more involved approach, following or combined with an exploratory framework, is the diagnostic framework. This approach requires extensive design, validated spectral datasets, combined with machine learning based on quantitative features, with the goal of autonomous classification of spectra from specific classes/treatments (Trevisan et al 2012). It should be noted that although conceptually separate, the exploratory framework almost always precedes or is used in conjunction with the diagnostic framework, as the development of diagnostic frameworks requires validation (discussed below) (Trevisan et al 2012). Common to both frameworks are processing steps including pre-processing, normalization, and computational analysis. Pre-processing and normalization are necessary to make spectra comparable to each other by minimizing the influence such as sample thickness and instrument variability (Martin et al 2010; Trevisan et al 2012; Baker et al 2014). Computational analysis as part of both exploratory and diagnostic frameworks make use of various chemometrics including univariate, multivariate, and ratio-metric analysis, which use single variable, multiple 
variables, or ratios of variables respectively (Trevisan et al 2012; Kumar et al 2016b). These approaches extract spectral 'biomarkers' (wavenumber variables) to serve as indicators of class or sample treatment (ex. normal, abnormal, and diseased) (Martin et al 2010; Kelly et al 2011b). Among these variables, extracting relevant ones consistent with sample treatment, rather than naturally occurring variance as is the often the case with biological samples, can be difficult. In cases where high naturally occurring heterogeneity exists, a combination of unsupervised data reduction steps combined with supervised methods focusing on the inter-sample differences has been effective. Among others, principal component analysis (PCA) and linear discriminant analysis (LDA) have been efficient at providing insight into natural population heterogeneity and class specific differences respectively (Martin et al. 2007; Martin et al 2010), as part of exploratory inquiry. Classifier algorithms including linear discriminant classifier (LDC) or support vector machines (SVM) are commonly used for biospectral datasets as part of diagnostic frameworks (Trevisan et al 2012). A large number of analysis models are available many of which can be combined to form composite techniques such as PCA-LDA or PCASVM (Trevisan et al 2012). Ultimately, the exact data analysis options are dependent on the questions set out to answer, in addition to the goals of individual research groups. Further details pertaining to computational analysis of biospectroscopy data, and considerations for exploratory and diagnostic frameworks, can be found elsewhere (Kelly et al 2011b; Trevisan et al 2012). Combined, the exploratory and diagnostic frameworks offer insight into the mechanistic biology of the study, while the diagnostic framework evaluates the classification accuracy of spectra belonging to specific sample classes. If the accuracy of a diagnostic framework is sufficiently high, it may warrant evaluation in automated decision-making platforms for subsequent use in high-throughput systems for commercial applications (Stables et al 2017).

As part of an effort to increase the biological relevance through mechanistic insight into molecular changes relating to spectral biomarkers, on which diagnostic and exploratory frameworks rely, catalogues of spectral markers for both MIR and Raman spectroscopy are available. These catalogues, originally published in 2007 for Raman and 2008 for MIR, are aimed at providing a guide for the interpretation of spectral bands, with recent updates to these spectral catalogues reflecting the increasing use of these 
spectroscopies (Movasaghi et al 2007; Movasaghi et al 2008; Talari et al 2015; Talari et al. 2016). In future, these will likely become available specifically for plant materials (Heredia-Guerrero et al 2014; Largo-Gosens et al. 2014). Biological spectra thus provide plant biologists with molecular level information, while providing industrial horticulturalists with rapid classification systems for detecting differences in sample material, thus contributing simultaneously to lab and field based applications.

\section{BIOSPECTROSCOPY FOR FUNDMENTAL PLANT RESEARCH AND APPLIED CROP SCIENCE}

\section{Valuable Plant Substances}

Preventing crop loss and improving our understanding of valuable substances for human consumption requires rapid identification and characterization of plant constituents in intact plants and crops as well as processed plant products. Plants are composed of, and produce, an impressive array of organic substances for human consumption as food and plant based bio-commodities. The quality of these substances often depends on the healthy growth and development of their respective plants, whether it is the plant itself that is the target substance, or a derivative product collected subsequently. Fruits and vegetables, medicinal compounds, phytonutrients beneficial for human health, as well as structural biopolymers are only a few examples of valuable plant substances for everyday use. In nature, primary metabolites, or core metabolites, such lipids, proteins, carbohydrates, and nucleic acids are essential for the healthy growth and development of all plant species; secondary metabolites, although not necessarily essential to survival, confer species specificity and provide specialized functions such as plant defence. Metabolites along with other classes of plant compounds thereby provide natural markers to study developmental and physiological processes in plants. Further, metabolites or other biochemical targets are quality indicators in horticultural processes and the food industry. Various primary and secondary metabolites, among other plant constituent compounds, are therefore important for research and industry (Rodriguez-Saona and Allendorf 2011; Lohumi et al 2015). This applies to valuable substances in processed materials, as well as to intact plant tissues. For a better understanding of the biochemical composition of crop plants and their products, continued identification, characterization, 
and quantification of the various classes of plant substances is necessary. Especially the development of non-destructive tools to analyse delicate and potentially highly heterogeneous samples such as fruits, vegetables, and whole plants, would facilitate improved crop cultivation and the production of valuable plant products. While the analysis of target plant substances is readily achieved in processed materials, tracking multiple plant substances simultaneously within whole tissues without destructive effects remains challenging.

Current uses demonstrate that biospectroscopy is adapted to study the abundance, distribution, and change of metabolites and other target substances in plants and crops. Biospectroscopy is specialized for measuring single or multiple compounds simultaneously, which has significantly contributed to a better understanding of plant constituents, valuable substances they produce, and how these substances change under both natural conditions and in response to physical and chemical processing. Specifically the food industry has used the sensitivity of IR and Raman spectroscopy extensively for quality control and detecting the corruption of various food products based on select compound detection and quantification (Rodriguez-Saona and Allendorf 2011; Lohumi et al 2015). However, most commercial food industry applications are limited to homogenous bulk samples such as oils, flours, and dairy (Karoui et al 2010). Transferring the food analytics application to more difficult specimens such as whole produce, without any sample manipulation remains difficult, although progress is being made using a number of economically important crops. Common plant metabolites have been characterized by IR and Raman spectroscopy including primary metabolites, such as amino acids (proteins), fatty acids (lipids), and carbohydrates besides secondary metabolites including phenolics, terpenoids, alkaloids, and polyacetylenes (Schulz and Baranska 2007; Baranska et al 2013). Biospectral analysis of primary metabolites within crop species include the measurement of wheat protein in kernels, lysine distribution in barley, and the study of temperature and water on gluten structure under processing conditions (Thygesen et al 2003; Georget and Belton 2006; Schulz and Baranska 2007). Lipid composition of many important plant oils has been investigated as related to the food industry (Schulz and Baranska 2007). Biospectral analysis of many common carbohydrates have been studied including the characterization of mono, di, and 
polysaccharides including cellulose (Schulz and Baranska 2007). Carbohydrates specifically have been studied in various tissues including crop species including apricot, carrot root, and onion (Bureau et al 2009; Baranska et al 2013). More recently, Raman spectroscopy was used to map changes in polysaccharide distribution in cell walls of apple during fruit development and senescence (Szymanska-Chargot et al 2016). While these present only a fraction of the literature available that pertains to primary metabolite analysis in crop species using biospectroscopy, they readily illustrate the capacity for metabolomics analysis based on primary metabolites that serve as both quality indicators and markers of dynamic biological processes.

Secondary metabolite analysis, specifically carotenoids have gained significant attention and have been extensively studied using biospectroscopy approaches. A common goal among these studies is the development of alternatives to more traditional analytical chemistry methods such as fractionation combined with gas and high pressure liquid chromatography (GC)/(HPLC), which require tissue destruction (Baranska et al 2006b; Kumar et al 2016a). Tomato fruits and related products such as juices have been focus points for biospectroscopy studies of plants, likely due to their nutritional value and relevance as a popular crop (Fu et al 2016; Radu et al 2016). Secondary metabolites associated with fruit ripening, including lycopene, $\beta$-carotene, phytoene and phytofluene, have been subject of study using MIR and Raman spectroscopy (Johnson et al 2003; Baranska et al 2006a; Ścibisz et al 2011; Trebolazabala et al 2013; Fu et al 2016; Radu et al 2016). Several of these studies have achieved metabolic profiling in whole tomato fruit, measuring metabolites such as lycopene, $\beta$-carotene, phytoene and phytofluene in whole tomato fruit without sample preparation (Trebolazabala et al 2013; Fu et al 2016). Raman spectroscopy may be exceptionally suited for this specific application, as these studies both used semi-portable systems capable of intact fruit analysis.

Metabolic profiling of valuable plant substances in vivo using biospectroscopy will help develop solutions for the quality control of crops and identify new targets for tracking physiological processes. Spectrochemical profiling using biospectroscopy will be especially useful in whole tissues, such as leaves and fruit, applied to physiological processes such as plant and fruit development, maturation, and decay. With this comes the potential application of biospectroscopy to contribute to molecular insight into the 
mechanism of plant and fruit development in vivo from the physiological perspective, while developing new quality control parameters for assessing delicate horticultural products. This in turn will facilitate application development for pre- and post-harvest sectors, where for example the real-time determination of development stage in the field may augment visual ripening scales, which remain the default standard (Mahlein 2016). As a result, better estimation of shelf life and related applications including the detection of defects in crops and produce, non-destructively and in real time, may become possible.

\section{Species Identification}

Valuable plant substances act as natural markers on which to identify and classify plant varieties and cultivars. As part of modern horticulture and plant research, it is desirable to identify, characterize, and classify plant varieties, cultivars, based on a number of sample types. Depending on the application, this may be from homogenous samples, such as processed products as part of food analytics, to larger specimens such as whole leaves. Because plant substances stretch over various levels of biological organization from single metabolites to whole plant organs, there are a many natural labels on which to identify species and classify them, as previously discussed, these natural label include metabolites and other non-metabolic plant substances. Species identification based on plant substances is readily achieved with biospectroscopy. There are many examples of species differentiation and chemical based taxonomic classification using biospectroscopy in a diverse set of cultivars. Further, species identification has been performed mainly on leaf and fruit tissues, with the unique exception of pollen. For most taxonomic studies to date using biospectroscopy, samples from plant organs like leaves are dried and or homogenized, suggesting the development for species identification in vivo under natural conditions. Among the many crops studied for species identification are mint, ginseng, olive, strawberry, and samples from various other plant species including Chinese ornamentals.

Rösch et al (2002) used Raman spectroscopy of stem cross sections successfully to characterize related mint species (Mentha sp.). Very recently, SERS-Raman spectroscopy was successfully applied to study inter-cultivar differences between Chinese ornamental (Chrysanthemum sp.) for taxonomic purposes (Zhang et al 2017). 
Rapid discrimination of strawberry cultivars based on homogenized fruits was also effectively performed (Kim et al 2009). Kim et al (2004) had also previously used MIR for the taxonomic discrimination of seven flower plant species based on homogenous samples. Similarly, homogenous dried leaf samples were subject to MIR analysis to distinguish plant populations and the effects of temperature on spectral features (Khairudin et al 2014). Aouidi et al (2012) also used ground leaf tissue to study and distinguish five Tunisian olive cultivars (Olea europaea) with MIR spectroscopy. Ages of ginseng cultivars were also determined based on biospectroscopy data, where as in most previous studies, samples where homogenized prior to analysis (Kwon et al 2014). ATR-FTIR on dried but intact sage leaves (Salvia officinalis) was performed by Gudi et al (2015) for more rapid taxonomic classification, where intact leaves represent more conserved tissue architecture. What is interesting is that analysis on whole hydrated leaves was performed close to a decade earlier. Ribeiro da Luz (2006) used hydrated whole intact leaves from 15 different native tree species in the Washington, DC area to assess the use of ATR-FTIR for classification of species. Using a spectral database, a classification accuracy of over $80 \%$ was achieved. This is particularly important as whole leaves are more representative samples compared to ground and homogenized tissue samples for the development of in vivo species identification. Uniquely, pollen has been used as a discriminating factor for species identification on two accounts; investigating both environmental effects as well as species differences in pollen from 300 plant species without sample manipulation (Zimmermann and Kohler 2014; Zimmerman et al 2015). Taken together, these studies show that whilst work is needed for in vivo species identification using biospectroscopy, chemical based taxonomy on a variety of samples is possible, including intact plant parts.

Biospectroscopy has contributed to method development for species identification and chemical based taxonomy from a number of plant samples with future applications in genotyping/phenotyping. Species identification on various levels of biological organization may prove useful to expedite the current time required for conventional phenotyping, which is approximately 10 years from initial screening to available cultivar (Mahlein 2016). As biospectroscopy is sensitive enough to detect changes within individual nucleotides, as well as over macroscopic areas, there is potential for both 
genotyping and phenotyping applications in practice (Ribeiro da Luz 2006; Kelly et al 2009; Kelly et al 2011a). However, the development of in vivo biospectroscopy is becoming a reality for various dynamic processes including physiological applications, which are readily transferrable to species identification and thus non-destructive phenotyping, or potentially even genotyping when combined with sample preparation (Kelly et al 2009; Kelly et al 2011a; Butler et al 2015).

\section{Plant Surface Structures}

The cuticle and cell wall contribute significantly to biospectroscopy measurements of intact plant tissues in vivo. As essential surface barriers, the cuticle and cell wall are conserved in all terrestrial plants and are intricately connected as part of the upper and lower epidermis. In their natural arrangements, the cuticle-cell wall layer consists of a complex matrix composed primarily of carbohydrates, proteins, and lipids (Dominguez et al 2011). While the main functions of the cuticle is to prevent water loss and regulate gas exchange, it is also involved in defending against light damage and microorganism invasion (Dominguez et al 2011). The cell wall defines cell shape and size and gives structural plasticity to plant cells; it is involved in plant growth, cellular differentiation, cell-cell communication, water regulation, and defence responses (Cosgrove 2005). Not only is the cell wall an essential barrier but also source of the most abundant natural biopolymer cellulose (Cosgrove 2005). Hence, the cell wall is both physiologically indispensable for plants and humans alike. Physiological and environmental cues influence the structure of both cuticle and cell wall, making these surface structures important subjects for plant and crop sciences. Yet the detailed biophysical properties of plant surface structures are difficult to discern and few methods exist to effectively study the molecular complexity of the cuticle and cell walls in their native arrangements where the two layers are elaborately intertwined (Dominguez et al 2011).

Biospectroscopy has offered a unique look at both cuticle and cell wall composition individually and together. The small penetration depth of MIR radiation into biological tissues requires characterization of plant surface structures such as the cuticle and cell wall. MIR radiation used by biospectroscopy methods penetrates between a 
several and several hundred micrometres into biological tissues depending on the method (Kazarian and Chan 2013; Butler et al 2015).

\section{Cuticle}

MIR and Raman spectroscopy has augmented advances in our knowledge of functional groups contained in the cuticle matrix, their structural roles, as well their macromolecular arrangement. Analysis of isolated cuticles was performed as early as 1992 by Chamel and Maréchal, as well as on tomato by Ramirez (1992). Subsequently several studies looking at both isolated cuticles and cuticles as part of natural plant structures such as leaves and fruit. Biospectroscopy of plant cuticles encompasses many important and economically relevant crop plant such as potato, grasses, and tomato, many of which have very different natural morphologies. Dubis et al (1999) used MIR in ATR mode as an analytical tool to investigate primarily carbonyl compounds associated with plant species and seasonal variation. This study included analysis of leaves from important crops including various cultivars of potato (Solanum tuberosum), beside several tree species. Dubis et al (2001) also studied cuticle wax composition in hops (Humulus lupulus). Cuticle fractions from olive leaf, pepper fruit, and apple fruit have also been investigated expanding the application to several important crop species (Johnson et al 2007). Progress towards in vivo applications of biospectroscopy for cuticle structure analysis for both agrochemical research and plant science has recently been made in the model organism Arabidopsis thaliana and a cuticle deficient mutant eciferuml (cer1) (Littlejohn et al 2015). Much of this work has led to understanding not only cuticle composition and constituent distribution, but also how cuticles change in response to exogenous factors, and during growth and development. To this end, spectroscopic characterization of plant cuticles and constituents including cutin, cutan, waxes, polysaccharides and phenolics, has recently been reviewed in detail by Heredia-Guerrero et al. (2014).

\section{Cell Wall}

Similar to plant cuticles, MIR spectroscopic analysis of plant cell walls was described over 25 years ago, likely owed to its significance in plant biology and industry (McCann et al 1992; Cosgrove 2005). In 1994, Séné et al published MIR spectroscopy of cell walls, comparing primary cell walls from onion (Allium cepa), carrot (Daucus carota), rice 
(Oryza sativa), sweet corn (Zea mays), and polypogon (Fugax steud), many of which are important crops. Since then, the number of biospectroscopy studies of cell walls has increased significantly. Cell walls from various plant organs including leaves, roots, and fruits have been characterized (Roesch et al 2002; Largo-Gosens et al 2014; White et al 2016). MIR has been used to study compositional changes resulting from growth and development, mutations in cell wall regulating genes of cellulose/hemi-cellulose, and lignin, as well as the effects of biotic and abiotic stress (Largo-Gosens et al 2014; Kumar et al 2016a). These studies give insight into the molecular structure of plant cell walls and changes therein in response to stimuli and contribute to our fundamental understanding of this and closely related structures. Industrial related processes such as spectral alterations associated with mechanical stress on plant cell walls, specifically cellulose and pectin orientation, was studied by Wilson et al. (2000). Recently, MIR and Raman spectroscopy were applied to characterizing non-cellulose polysaccharides from cell wall fractions of tomato during development (Chylinska et al 2016). Hence, plant cuticle and cell wall have been studied by biospectroscopy in both structure and function and under different conditions relevant to biological and industrial processes.

\section{Cuticle and Cell Wall Together}

Cuticle and cell walls are studied together when tissues such as leaves and fruit are measured without manipulation (Figure 2). This is similar to studies on non-isolated cuticles, as part of whole plant organs such as freshly cut leaves. Analysis of leaves by MIR and Raman interrogates the cuticle, and palisade parenchyma of the adaxial leaf surface, respectively (Butler et al 2015). Even ATR-FTIR spectroscopy, which penetrates only between $1-5 \mu \mathrm{m}$ into the surface of plant structures, this has been sufficient to effectively measure leaves from 32 tree species and identify them with good accuracy (Ribeiro da Luz 2006; Kazarian and Chan 2013). These studies demonstrate the versatility of biospectroscopy for cuticle and cell wall characterization separately and as combined layers as part of plant organs. Further work is needed to increase the study of plant cuticles and cell walls in vivo, and while biospectroscopy has contributed to this endeavour, analysis of whole plants, rather than freshly harvested leaves, remains elusive (Butler et al 2015). 


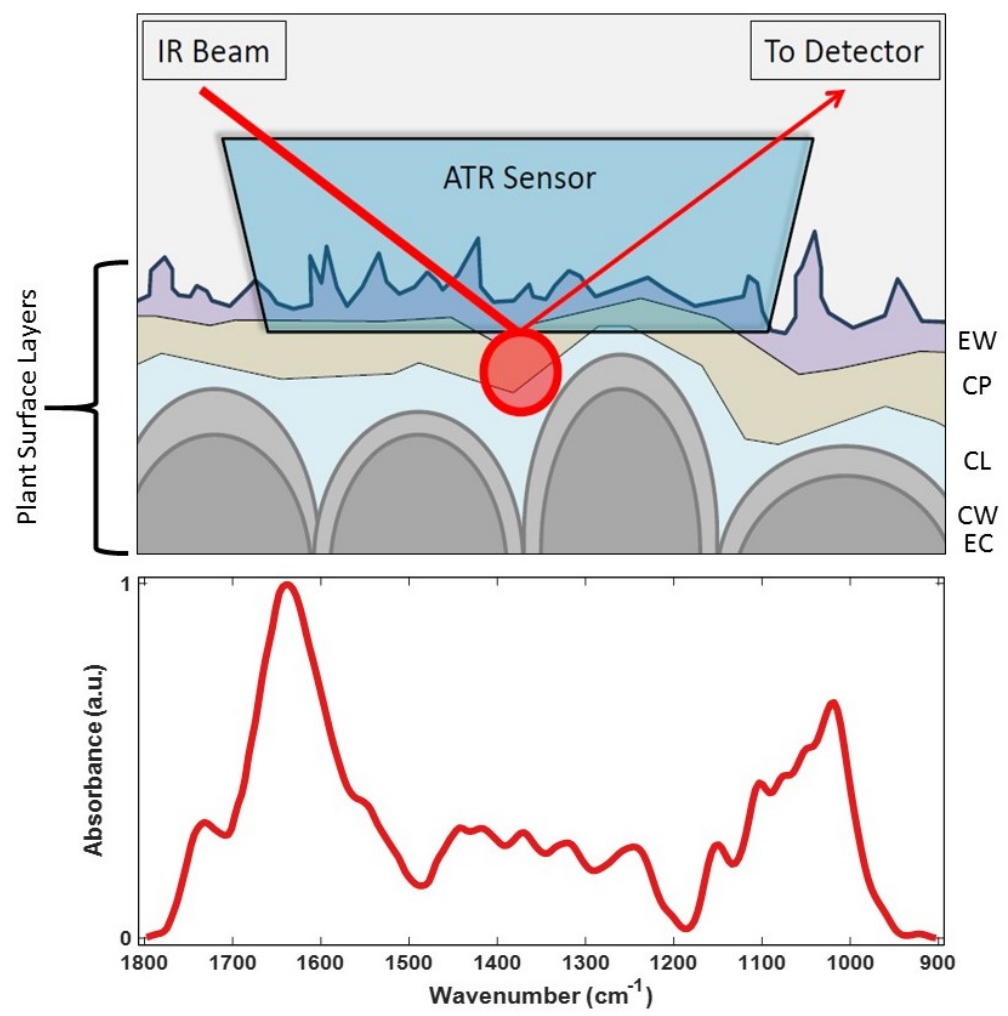

Figure 2: TOP: Conceptual schematic of ATR-FTIR measurement on plant surface structures (top) EW; epicuticular waxes; CP; cuticle proper; CL cuticluar layer; CW; cell wall; EC; epidermal cell. BOTTOM: Seventy averaged ATR-FTIR spectra of 4 week old fully expanded tomato leaf (Solanum lycopersicum cv. moneymaker) over the fingerprint region $\left(1800-900 \mathrm{~cm}^{-1}\right)$.

Work done thus far on the surface structure of plants will aid the development of biospectroscopy for examining the cuticle and cell wall within whole plants and fruit and how these layers change in response to various processes, both naturally and during crop cultivation. The ability to measure whole plant organs such as leaves and extract spectroscopic information relevant to physiological processes suggests that applications to crop monitoring in whole plants in the field or whole fruit before, at, or after harvest is becoming a strong probability. Recent progress with methods such as ATR-FTIR and Raman spectroscopy have shown that surface structures including cuticle and cell wall in leaves of whole plants and whole fruit can be measured without destructive effects entirely in vivo (Trebolazabala et al 2013; Butler et al 2015; Fu et al 2016). It has been clear for more than two decades that biospectroscopy methods can contribute to our detailed understanding of important plant surface structures including the cuticle and cell 
walls in the lab, but development of biospectroscopy for complete in vivo analysis of plants will expand its application potential significantly into the area of commercial horticulture for physiological based monitoring of plants and crops.

\section{Plant-Environment Interactions}

Growth and development of plants, in their natural habitat or in fields and greenhouses, is dictated in large part by their interaction with the external environment. When the environment becomes unfavourable, plants employ stress and defence responses to cope with sub-optimal environmental conditions. In the light of climate change, the dynamic interaction between pathogens and the environment has become an important consideration (Nutter Jr. 2010). Climate change and resulting effects, likely influence the contribution of individual pests to annual crop loss (Figure 3). 


\section{Global Crop Loss to Pests}

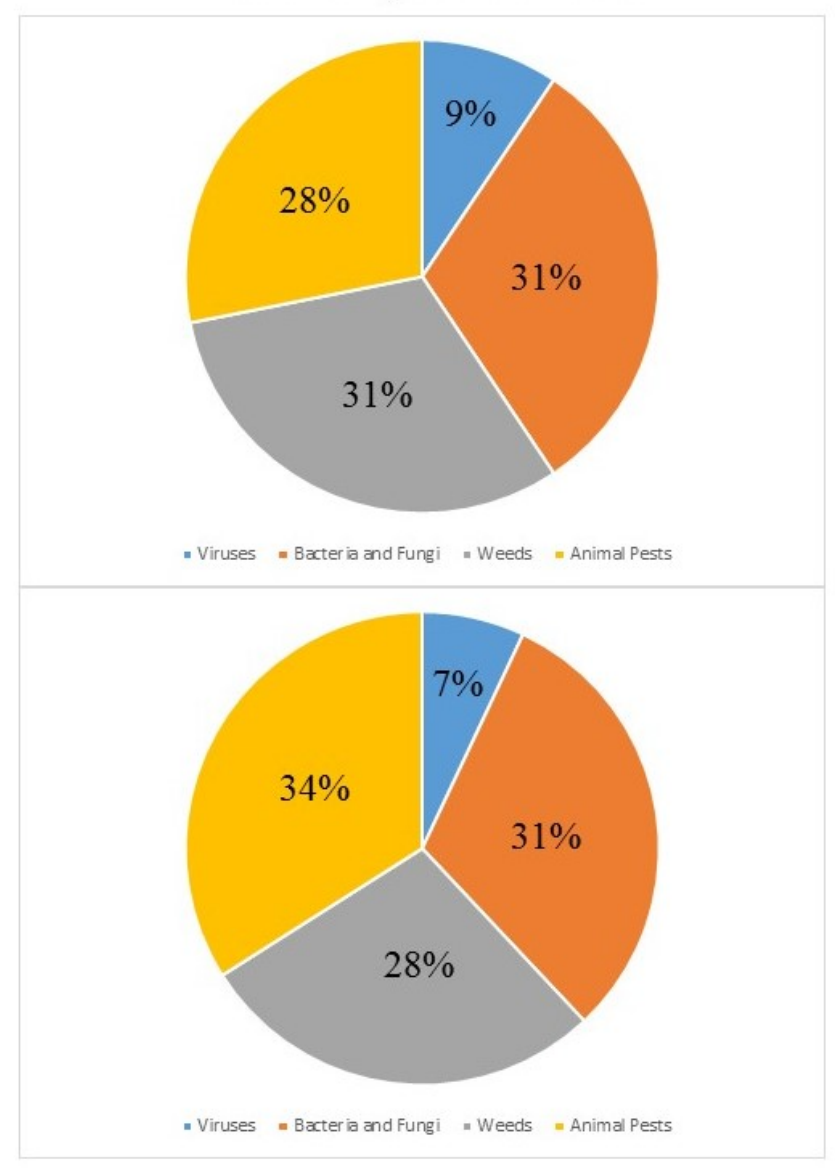

Figure 3: Contributions of pest and pathogen types to annual global crop loss. Top: Crop loss to pests and pathogens for wheat, rice, maize, barley, potatoes, soybean, sugar beet and cotton, for the years 1996-1998 (Adapted from Oerke and Dehne 2004). Bottom: Crop loss to pests and pathogens for wheat, rice, maize, potatoes, soybean, and cotton for the years 2001-2003 (Adapted from Oerke 2006).

Both abiotic and biotic factors influence plant physiology, growth, and development and thus crop quality and yield (Suzuki et al 2014). Pertinent abiotic factors influencing plants include: drought, salinity, temperature, nutrient deficiency, phototoxicity, ozone $\left(\mathrm{O}_{3}\right)$ and anaerobic stresses (Suzuki et al 2014) (see also Figure 1). Viruses, bacteria, fungi, nematodes, weeds and herbivores are among the main biotic 
factors relevant to plant survival (Atkinson and Urwin 2012). Under natural or field conditions, combinations of abiotic and or biotic stress occur where different stress types may positively or negatively affect each other (Atkinson and Urwin 2012). Furthermore, plant response to abiotic and biotic stressors overlap on the molecular level, sharing general response elements such as signalling pathways, while differing in fine tuned specific responses to individual stressors (Bostock et al 2014; Kissoudis et al 2014). Because stress responses precede plant disease, understanding the mechanisms of plant response to individual stresses and in combination could be especially useful for determining 'biomarkers of stress effects', while plants are still in the reversible stage of stress (Bostock et al 2014). During this acclimation stage, natural tolerance/resistance to stress prevent adverse effects, which once exhausted lead to irreversible strain, disease, and ultimately plant death. For precision crop protection and the prevention of plant disease caused by both abiotic and biotic stress, the preventative stages of plant disease, namely the acclimation/resistance stage, may be a specifically suitable target for biospectroscopy. Pre-symptomatic disease detection would have the added benefit of optimizing crop protection measures and reducing the overuse of harmful pesticides, which are becoming an increasing public concern. Detection and characterization of stress responses before irreversible damage ensues would be beneficial for a number of reasons including concomitant development of health monitoring tools. Elucidation of the intricacies of individual and overlapping stress responses by plant biologists would significantly aid in determining targets suitable as 'stress biomarkers' in different crop species. Crop scientist in turn may be able to apply biological stress markers for early disease detection and identifying plants particularly resistant or tolerant to different stresses. Indeed both disease detection and phenotyping are among the most important research areas for modern horticulture concerning plant and crop scientists collectively. Alternatively, direct detection of visually undetectable pests such as microscopic pathogens is also a priority, even though pathogen density is not necessarily indicative of disease severity for plants in the field (Nutter Jr. et al 2010; Mahlein 2016). While direct pathogen detection may be difficult in the field, it may be more readily applied to postharvest storage and transport of plant produce, where infected or contaminated products pose potential health hazards. Thus from the view of researchers, there is a desire to 
discern the details of individual and stress combinations, both abiotic and biotic, in order to identify key factors of plant stress early before damage is done. With the right technology, these key factors or biomarkers could help horticulturalists in their quest to reduce pre and post-harvest crop loss as a result of plant disease. It is noteworthy, that disease detection by default coincides with the development of health monitoring tools, as the control subjects used to study disease are defined as healthy counterparts within individual studies.

Many applications of biospectroscopy have displayed its capacity to contribute to the areas of plant disease detection and health monitoring, through the investigation of biotic and abiotic stress, together with closely linked processes like leaf senescence. Linked to natural development, ageing, and disease is the process of senescence, which has also been studied using biospectroscopy methods. The process of senescence is important because it is induced by several factors including stress, and also occurs naturally as plants mature (Gepstein and Glick 2013). Leaf senescence has been studied in situ on detached leaves of black cherry (Prunus serotina), sweet pepper (Clethra alnifolia), Capsicum annuum, and Nicotiana tabacum using ATR-FTIR spectroscopy (Ivanova and Singh 2002). ATR-FTIR spectroscopy has also been used in vivo on leaves of whole plants to study plant growth and development including cell expansion and senescence (Butler et al 2015).

Several main abiotic and abiotic stresses have been investigated in various plants including crops like wheat and tomato. Raman spectroscopy was applied to study mechanistic changes related drought stress induced by cutting leaves from spring wheat plants (Wesełucha-Birczynska et al 2012); where drought stress in wheat is particularly relevant to horticultural challenges worldwide (Suzuki et al 2014). Assessment of salt stress has been conducted on both plants and fruit. Salt tolerant halophytes, ice plants (Mesembryanthemum crystallinum), where compared to Arabidopsis thaliana under salt stress conditions and investigated using MIR spectroscopy (Yang and Yen 2002). Metabolic-fingerprinting of tomato fruit extracts grown under high salt stress and normal conditions was investigated by Johnson et al 2003. Salt stress and the effects on cell wall structure and leaf cell anatomy in coffee (Coffea arabica) has also been recently 
investigated (de Lima et al 2014). Khairudin et al (2014) investigated variable temperature on populations of the herb Polygonum minus and observed differences in important metabolites including flavonoids. Biospectroscopy to study nutrient stress has only been applied in specialized settings to our knowledge. Interestingly, algae (Micrasterias $s p$.) have also served as a model system for biospectroscopy in which in vivo analysis, nutrient stress, and other anthropogenic abiotic stresses, have been studied (Heraud et al 2005; Patel et al 2008). The effects of nutrient stress was studied using Raman spectroscopy on live algal cells in vivo, where the study was additionally used to compare data pre-processing effects on outcomes of computational analysis (Heraud et al 2005). Transmission MIR using synchrotron radiation was employed on live and fixed tissue of the model plant Asiatic dayflower (Commelina communis) specifically to detect Calcium deficiency (Butler et al 2017). Metal stress was investigated through early effects of Cadmium stress, and subsequent partial recovery, in clover (Trifolium sp.) leaves using MIR (Wei et al 2009), as well as by Liu et al (2014), who similarly to de Lima et al (2014), correlated changes in cell wall structure with changes in leaf anatomy but in navel orange plants (Citrus sinensis). Ozone stress, as well as both biotic and abiotic stresses were measured on Sycamore tree (Acer pseudoplatanus) leaves exposed to air pollution, ozone, and fungal infection, giving potential mechanistic insight into shared stress responses such as reactive oxygen species (ROS) generation (Ord et al 2016).

Studies of biotic stresses such as viruses, bacteria, and fungal pathogens, using biospectroscopy remains relatively limited to date but progress has been made in the presymptomatic detection of disease. Investigations into biotic stress scenarios have also been selectively performed with several applications directed at pre-symptomatic disease detection and health monitoring in plants and trees. Biospectroscopy studies into biotic stress caused by fungal pathogens includes the tar spot leaf fungus (Rhytisma acerinum) on Sycamore tree leaves by Ord et al. (2016). Plant-plant interference through metabolic profiling to study interspecies competition between a monocotyledon Brachypodium distachyion and a dicotyledon Arabidopsis thaliana, has been described by Gidman et al 2003, with potential applications to weed pests. 
Progress has been made in both plant health monitoring and disease detection, to demonstrate the applicability of biospectroscopy in these areas. Recently, MIR photoacoustic spectroscopy was used for pre-symptomatic detection of powdery mildew infection in Rubus corchorifolius, a Korean raspberry cultivar (Du and Zhou 2015). Previously, ATR-FTIR spectroscopy as a potential tool in huanglongbing and citrus variegated chlorosis diagnosis in leaves of sweet orange trees was explored (do Brasil Cardinali et al 2012). Finally, and among the most recent developments has been the successful health monitoring of whole tomato plants. ATR-FTIR spectroscopy and Raman spectroscopy have been used, in combination, for the successful and nondestructive monitoring of healthy plant growth and development in intact tomato plants (Solanum lycopersicum) (Butler et al 2015). This study was performed entirely in vivo on plant leaves, where spectral were consistent with major physiological processes including cell expansion in newer leaves and senescence in more mature leaves.

Taken together, the above studies show a significant contribution to an exceptionally diverse set of plant varieties and cultivars subject to various stress or disease conditions. Although as previously explained, the transfer of these studies to applied crop sciences, requires further development of fully in vivo analysis. However, the progress to date prompt the further evaluation of biospectroscopy approaches to study plant-environment interactions, including, effects of abiotic and biotic stresses, progression of disease, as well as complementary processes such as healthy development and natural senescence. Ultimately, the transition to a full non-destructive sensor technology will be met once certain technical limitations are overcome.

\section{CHALLENGES AND LIMITATIONS}

Development of biospectroscopy as an applied sensor technology requires portable instrumentation. There is no doubt that lab-based biospectroscopy instruments have contributed significantly to the plant laboratory, yet despite the availability of fully portable equipment, no commercial applications have been developed. Laboratory based IR spectrometers rarely accommodate the analysis of whole plants, specifically in fields and semi-controlled environments (CE rooms, glasshouses, etc.), and part of the reason why biospectroscopy applications require some form of sample preparation, limiting it as 
a potential field sensor. Fully portable instruments are available for biospectroscopy, and while these have existed for some time, they have to our knowledge gone without evaluation. For only a few examples of fully portable systems commercially available for material science and related purposes, see (http://bwtek.com/technology/raman) and (https://www.agilent.com/en/products/ftir/ftir-compact-portable-systems) for Raman and MIR respectively. Both Raman and MIR offer variable attachments for customized uses. Thus as part of the challenge of validating different instrument configurations, fully portable units currently advertised for more traditional material science applications, have to be evaluated for plant materials in the field. Especially because evaluating these instruments could significantly accelerate the development of fully portable biospectroscopy sensor systems for plants. Additionally, portable equipment comparisons with lab based spectrometers, would contribute to the issue of validating tentative spectral biomarkers generated in the lab, under field conditions. Figure 4 shows challenges and considerations with regard to differences between laboratory and field, which are generally applicable to technologies hoping to bridge the gap between lab and filed applications.

$\underline{\text { Laboratory Conditions }}$

\begin{tabular}{c} 
Single Stress \\
Controlled Environment \\
Single Stress-High Intensity \\
Single Developmental Stage \\
Model Organisms \\
Standard Soil Conditions \\
Limited Soil Volume \\
\hline
\end{tabular}

\section{Field Conditions}

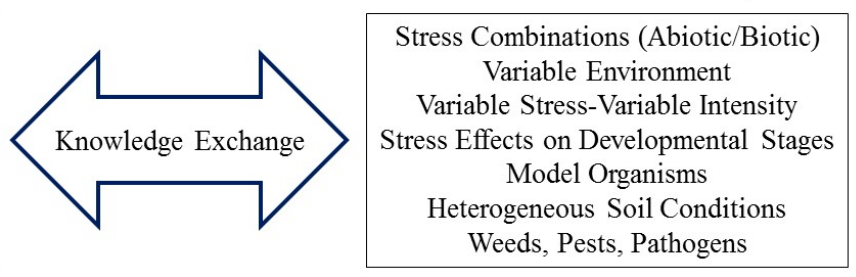


Figure 4: Differences in complexity between laboratory and field conditions showing considerations for knowledge exchange between lab-based and field-based systems

(Adapted from Suzuki et al 2014).

The number of available options for sample preparation, spectral acquisition, and data analysis, makes standardizing biospectroscopy approaches difficult leading to the need for extensive validation before technologies become commercially viable. This can be seen as analogous to the different conditions present within controlled laboratories compared very high variability seen under field conditions. Due to the versatility of biospectroscopy methods, most studies use different instruments and data analysis tools. Therefore, spectral wavenumbers, extracted and listed as part of a study, are influenced by the experimental design and instrument choice, which can make it difficult to compare different studies. Consequently, this may hinder the knowledge transfer and progression of biospectroscopy into routine application. In light of this, validation is needed to confirm spectral wavenumbers intended to act as 'biomarkers of effect', many of which are tentatively assigned, due to the intrinsic ambiguity of extrapolating from individual bond vibrations to physiological effects. To augment the progression of biospectroscopy towards industry application past its current uses, validation with complementary methods ranging from traditional methods like chromatography, to other optical sensors and OMICs technologies (genomics, proteomics, metabolomics, lipidomics, etc.) that like biospectroscopy rely on multi component analysis of various classes of biomolecules. In any case, before routine biospectroscopy applications are available, more standardized approaches, as well as combinatorial data analysis approach combining multiple lines of experimental inquiry, are imperative (Figure 5). 


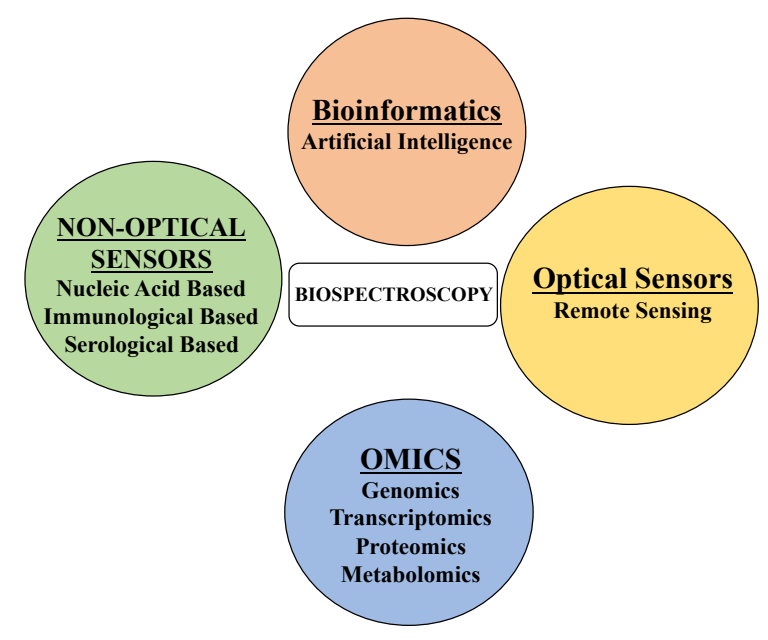

Figure 5: Complementary data for Biospectroscopy validation and future integration of these technologies as part of a multi-sensor platform.

\section{CONCLUSIONS AND FUTURE PERSPECTIVES}

Biospectroscopy is suitably matched to study the fundamental processes important for crop protection and will help bridge the gap between lab and field applications by facilitating interdisciplinary research through knowledge transfer. To tackle the many challenges surrounding crop production and supply, innovative solutions to crop loss and food waste in the food system are paramount. Closely linked to crop protection is our understanding of the biological processes influencing plant development, as well as the details of plant composition as related to valuable plant substances. The natural complexity of plants, and the extraction of valuable substances for products, means that no single technology will fill the gap, to produce more with less, currently challenging modern agriculture. However, in meeting the challenge to fill the gaps leading to losses in plant resources, priority will likely be given to methods that yield highly specific data rapidly without destructive effects to delicate biological samples. To this end, many nondestructive optical sensor technologies are under evaluation, sharing common goals pertaining to crop protection and phenotyping (Mahlein 2016). As mentioned, these goals include disease detection; species identification for phenotyping and taxonomic classification; and increasing mechanistic insight into plant physiology and disease 
(Mahlein 2016). Further, Lucas (2011) (see also Crute 2003) outlined criteria for a truly sustainable technology in the context of agricultural productivity:

1. Based on the use of one or more renewable resources

2. Does not break down due to evolutionary change

3. Has a broad spectrum of applicability

4. Is affordable in the context of the local economy and crop value

It becomes immediately clear from this discussion and previous developments that biospectroscopy meets at least the first three points of these criteria. And while affordability is still to be determined in this context, biospectroscopy certainly remains a strong candidate sensor for development. The progression of biospectroscopy from its humble beginnings in the analytical and material science laboratories, for basic compound analysis, has expanded rapidly into the areas of plant and crop sciences for the analysis of complex biological materials. The many functions of biospectroscopy in the plant laboratory, whose principles potentially extend to applications in the field, are plentiful. Biospectroscopy has demonstrated its capacity to meet many of the criteria needed to fulfil specific goals within the plant, crop, and food sciences, which has warranted its development towards an applied sensor technology for industry. Despite scarce applications to intact plant systems in vivo, there remains exciting potential for biospectroscopy especially in expanding these applications. Once challenges, including validation of fully portable instruments, are successfully overcome, through integration of biospectroscopy data with complementary methods, it may become a broadly applicable and commercially available technology for analysis and diagnosis.

While most biospectroscopy studies analyse primarily solid or semi-solid samples, there are future prospects in other prominent areas of plant and crop science, which would benefit from gas and liquid sampling modes of IR spectroscopy. Specific examples here include the analysis of VOCs such as isoprene, which have become compounds of interest, due to their apparent ecological and defence functions (Dudareva et al 2013). Liquid based biospectroscopy may prove useful for the investigation of changes in the composition of plant biofluids, xylem and phloem sap. Biofluid analysis is 
currently a major topic in the biomedical area of biospectroscopy (Baker et al 2016b), where 'liquid biopsies' performed on plants may be a knowledge exchange opportunity between plant and biomedical sciences. Another area of interest will be the development and combination of artificial intelligence with biospectroscopy, where computers will autonomously take on all data analysis and processing without any external subjective influence (Figure 5). 


\section{References}

Andrews, David (2014) Molecular Photophysics and Spectroscopy. Morgan and Claypool Publishers. ISBN 978-1-627-05287-0

Aouidi, F., Dupuy, N., Artaud, J., Roussos, S., Msallem, M., Perraud-Gaime, I., ... Hamdi, M. (2012). Discrimination of five Tunisian cultivars by Mid InfraRed spectroscopy combined with chemometric analyses of olive Olea europaea leaves. Food Chemistry, 131(1), 360-366.

Atkinson, N. J., and Urwin, P. E. (2012). The interaction of plant biotic and abiotic stresses: from genes to the field. Journal of Experimental Botany, 63(10), 3523-3543.

Baker, M. J., Hughes, C. S., and Hollywood, K. A. (2016a) Biophotonics: Vibrational Spectroscopic Diagnostics.

Baker, M. J., Hussain, S. R., Lovergne, L., Untereiner, V., Hughes, C., Lukaszewski, R. A., ... Sockalingum, G. D. (2016b). Developing and understanding biofluid vibrational spectroscopy: a critical review. Chemical Society Reviews, 45(7), 1803-1818.

Baker, M. J., Trevisan, J., Bassan, P., Bhargava, R., Butler, H. J., Dorling, K. M., ... Hughes, C. (2014). Using Fourier transform IR spectroscopy to analyze biological materials. Nature Protocols, 9(8), 1771-1791.

Baranska, M., Roman, M., Schulz, H., and Baranski, R. (2013). Recent advances in Raman analysis of plants: alkaloids, carotenoids, and polyacetylenes. Current Analytical Chemistry, 9(1), 108-127.

Baranska, M., Schütze, W., and Schulz, H. (2006a). Determination of lycopene and $\beta$ carotene content in tomato fruits and related products: comparison of FT-Raman, ATRIR, and NIR spectroscopy. Analytical Chemistry, 78(24), 8456-8461.

Baranska, M., Schulz, H., Joubert, E., and Manley, M. (2006b). In situ flavonoid analysis by FT-Raman spectroscopy: Identification, distribution, and quantification of aspalathin in green rooibos (Aspalathus linearis). Analytical Chemistry, 78(22), 7716-7721.

Bostock, R. M., Pye, M. F., and Roubtsova, T. V. (2014). Predisposition in plant disease: exploiting the nexus in abiotic and biotic stress perception and response. Annual Review of Phytopathology, 52, 517-549.

Bureau, S., Ruiz, D., Reich, M., Gouble, B., Bertrand, D., Audergon, J. M., and Renard, C. M. (2009). Application of ATR-FTIR for a rapid and simultaneous determination of sugars and organic acids in apricot fruit. Food Chemistry, 115(3), 1133-1140.

Bureau, S., Ścibisz, I., Le Bourvellec, C., and Renard, C. M. (2012). Effect of sample preparation on the measurement of sugars, organic acids, and polyphenols in apple fruit by mid-infrared spectroscopy. Journal of Agricultural and Food Chemistry, 60(14), 3551-3563.

Butler, H. J., Adams, S., McAinsh, M. R., and Martin, F. L. (2017). Detecting nutrient deficiency in plant systems using synchrotron Fourier-transform infrared 
microspectroscopy. Vibrational Spectroscopy, 90, 46-55.

Butler, H. J., Ashton, L., Bird, B., Cinque, G., Curtis, K., Dorney, J., ... Walsh, M. J. (2016). Using Raman spectroscopy to characterize biological materials. Nature Protocols, 11(4), 664-687.

Butler, H. J., McAinsh, M. R., Adams, S., and Martin, F. L. (2015). Application of vibrational spectroscopy techniques to non-destructively monitor plant health and development. Analytical Methods, 7(10), 4059-4070.

Chamel, A., and Maréchal, Y. (1992). Characterization of isolated plant cuticles using Fourier transform infrared (FTIR) spectroscopy. Comptes rendus de l'Académie des Sciences. Série 3, Sciences de la vie, 315(10), 347-354.

Chylińska, M., Szymańska-Chargot, M., and Zdunek, A. (2016). FT-IR and FT-Raman characterization of non-cellulosic polysaccharides fractions isolated from plant cell wall. Carbohydrate Polymers, 154, 48-54.

Cosgrove, D. J. (2005). Growth of the plant cell wall. Nature Reviews Molecular Cell Biology, 6(11), 850-861.

Crute, I. R. (2003, November). Increased crop productivity from renewable inputs-a scientific challenge for the 21st century. In BCPC International Congress Crop Science and Technology. Proceedings of an International Congress held at the SECC, Glasgow, Scotland, UK, 10 (pp. 3-14).

de Lima, R. B., dos Santos, T. B., Vieira, L. G. E., Ferrarese, M. D. L. L., FerrareseFilho, O., Donatti, L., ... de Oliveira Petkowicz, C. L. (2014). Salt stress alters the cell wall polysaccharides and anatomy of coffee (Coffea arabica L.) leaf cells. Carbohydrate Polymers, 112, 686-694.

do Brasil Cardinali, M. C., Boas, P. R. V., Milori, D. M. B. P., Ferreira, E. J., e Silva, M. F., Machado, M. A., and Bellete, B. S. (2012). Infrared spectroscopy: a potential tool in huanglongbing and citrus variegated chlorosis diagnosis. Talanta, 91, 1-6.

Domínguez, E., Heredia Guerrero, J. A., and Heredia, A. (2011). The biophysical design of plant cuticles: an overview. New Phytologist, 189(4), 938-949.

Dubis, E. N., Dubis, A. T., and Popławski, J. (2001). Determination of the aromatic compounds in plant cuticular waxes using FT-IR spectroscopy. Journal of Molecular Structure, 596(1), 83-88.

Dubis, E. N., Dubis, A. T., and Morzycki, J. W. (1999). Comparative analysis of plant cuticular waxes using HATR FT-IR reflection technique. Journal of Molecular Structure, $511,173-179$.

Du, C., and Zhou, J. (2015). Fourier Transform Mid-Infrared Photoacoustic Spectroscopy for Presymptomatic Detection of Powdery Mildew Infection in Rubus corchorifolius L. Spectroscopy Letters, 48(8), 610-615. 
Dudareva, N., Klempien, A., Muhlemann, J. K., and Kaplan, I. (2013). Biosynthesis, function and metabolic engineering of plant volatile organic compounds. New Phytologist, 198(1), 16-32.

Fu, X., He, X., Xu, H., and Ying, Y. (2016). Nondestructive and rapid assessment of intact tomato freshness and lycopene content based on a miniaturized Raman spectroscopic system and colorimetry. Food Analytical Methods, 9(9), 2501-2508.

Georget, D. M., and Belton, P. S. (2006). Effects of temperature and water content on the secondary structure of wheat gluten studied by FTIR spectroscopy. Biomacromolecules, 7(2), 469-475.

Gerland, P., Raftery, A. E., Ševčíková, H., Li, N., Gu, D., Spoorenberg, T., ... Bay, G. (2014). World population stabilization unlikely this century. Science, 346(6206), 234237.

Gepstein, S., and Glick, B. R. (2013). Strategies to ameliorate abiotic stress-induced plant senescence. Plant Molecular Biology, 82(6), 623-633.

Gidman, E., Goodacre, R., Emmett, B., Smith, A. R., and Gwynn-Jones, D. (2003).

Investigating plant-plant interference by metabolic fingerprinting. Phytochemistry, 63(6), 705-710.

Gierlinger, N., Keplinger, T., and Harrington, M. (2012). Imaging of plant cell walls by confocal Raman microscopy. Nature Protocols, 7(9), 1694-1708.

Godfray, H. C. J., Beddington, J. R., Crute, I. R., Haddad, L., Lawrence, D., Muir, J. F., ... Toulmin, C. (2010). Food security: the challenge of feeding 9 billion people. Science, $327(5967), 812-818$.

Gudi, G., Krähmer, A., Krüger, H., and Schulz, H. (2015). Attenuated Total ReflectanceFourier Transform Infrared Spectroscopy on Intact Dried Leaves of Sage (Salvia officinalis L.): Accelerated Chemotaxonomic Discrimination and Analysis of Essential Oil Composition. Journal of Agricultural and Food Chemistry, 63(39), 8743-8750.

Heraud, P., Wood, B. R., Tobin, M. J., Beardall, J., and McNaughton, D. (2005). Mapping of nutrient-induced biochemical changes in living algal cells using synchrotron infrared microspectroscopy. FEMS Microbiology Letters, 249(2), 219-225.

Heredia-Guerrero, J. A., Benítez, J. J., Domínguez, E., Bayer, I. S., Cingolani, R., Athanassiou, A., and Heredia, A. (2014). Infrared and Raman spectroscopic features of plant cuticles: a review. Frontiers in Plant Science, 5, 305.

Holman, H. Y. N., Bechtel, H. A., Hao, Z., and Martin, M. C. (2010). Synchrotron IR spectromicroscopy: chemistry of living cells.

IFPRI, Development Initiatives. (2017). Global Nutrition Report 2017: Nourishing the SDGs. Bristol, UK: Development Initiatives Poverty Research Ltd.

Ivanova, D. G., and Singh, B. R. (2003). Nondestructive FTIR monitoring of leaf senescence and elicitin induced changes in plant leaves. Biopolymers, 72(2), 79-85. 
Johnson, H. E., Broadhurst, D., Goodacre, R., and Smith, A. R. (2003). Metabolic fingerprinting of salt-stressed tomatoes. Phytochemistry, 62(6), 919-928.

Johnson, E. J., Dorot, O., Liu, J., Chefetz, B., and Xing, B. (2007). Spectroscopic characterization of aliphatic moieties in four plant cuticles. Communications in Soil Science and Plant Analysis, 38(17-18), 2461-2478.

Kaminskyj, S., Jilkine, K., Szeghalmi, A., and Gough, K. (2008). High spatial resolution analysis of fungal cell biochemistry-bridging the analytical gap using synchrotron FTIR spectromicroscopy. FEMS Microbiology Letters, 284(1), 1-8.

Karoui, R., Downey, G., and Blecker, C. (2010). Mid-infrared spectroscopy coupled with chemometrics: A tool for the analysis of intact food systems and the exploration of their molecular structure- Quality relationships-A review. Chemical Reviews, 110(10), 61446168.

Kazarian, S. G., and Chan, K. A. (2013). ATR-FTIR spectroscopic imaging: recent advances and applications to biological systems. Analyst, 138(7), 1940-1951.

Kelly, J. G., Martin-Hirsch, P. L., and Martin, F. L. (2009). Discrimination of base differences in oligonucleotides using mid-infrared spectroscopy and multivariate analysis. Analytical Chemistry, 81(13), 5314-5319.

Kelly, J. G., Najand, G. M., and Martin, F. L. (2011a). Characterisation of DNA methylation status using spectroscopy (mid IR versus Raman) with multivariate analysis. Journal of Biophotonics, 4(5), 345-354.

Kelly, J. G., Trevisan, J., Scott, A. D., Carmichael, P. L., Pollock, H. M., Martin-Hirsch, P. L., and Martin, F. L. (2011b). Biospectroscopy to metabolically profile biomolecular structure: a multistage approach linking computational analysis with biomarkers. Journal of Proteome Research, 10(4), 1437-1448.

Khairudin, K., Sukiran, N. A., Goh, H. H., Baharum, S. N., and Noor, N. M. (2014). Direct discrimination of different plant populations and study on temperature effects by Fourier transform infrared spectroscopy. Metabolomics, 10(2), 0.

Kim, S. W., Ban, S. H., Chung, H., Cho, S., Chung, H. J., Choi, P. S., ... Liu, J. R. (2004). Taxonomic discrimination of flowering plants by multivariate analysis of Fourier transform infrared spectroscopy data. Plant Cell Reports, 23(4), 246-250.

Kim, S. W., Min, S. R., Kim, J., Park, S. K., Kim, T. I., and Liu, J. R. (2009). Rapid discrimination of commercial strawberry cultivars using Fourier transform infrared spectroscopy data combined by multivariate analysis. Plant Biotechnology Reports, 3(1), 87-93.

Kissoudis, C., van de Wiel, C., Visser, R. G., and van der Linden, G. (2014). Enhancing crop resilience to combined abiotic and biotic stress through the dissection of physiological and molecular crosstalk. Frontiers in Plant Science, 5.

Kumar, S., Lahlali, R., Liu, X., and Karunakaran, C. (2016a). Infrared spectroscopy combined with imaging: A new developing analytical tool in health and plant science. Applied Spectroscopy Reviews, 51(6), 466-483. 
Kumar, S., Verma, T., Mukherjee, R., Ariese, F., Somasundaram, K., and Umapathy, S. (2016b). Raman and infra-red microspectroscopy: towards quantitative evaluation for clinical research by ratiometric analysis. Chemical Society Reviews, 45(7), 1879-1900.

Kwon, Y. K., Ahn, M. S., Park, J. S., Liu, J. R., In, D. S., Min, B. W., and Kim, S. W. (2014). Discrimination of cultivation ages and cultivars of ginseng leaves using Fourier transform infrared spectroscopy combined with multivariate analysis. Journal of Ginseng Research, 38(1), 52-58.

Largo-Gosens, A., Hernández-Altamirano, M., García-Calvo, L., Alonso-Simón, A., Álvarez, J., and Acebes, J. L. (2014). Fourier transform mid infrared spectroscopy applications for monitoring the structural plasticity of plant cell walls. Frontiers in Plant Science, 5, 303.

Littlejohn, G. R., Mansfield, J. C., Parker, D., Lind, R., Perfect, S., Seymour, Moger, J. (2015). In vivo chemical and structural analysis of plant cuticular waxes using stimulated Raman scattering microscopy. Plant Physiology, 168(1), 18-28.

Liu, G., Dong, X., Liu, L., Wu, L., and Jiang, C. (2014). Boron deficiency is correlated with changes in cell wall structure that lead to growth defects in the leaves of navel orange plants. Scientia Horticulturae, 176, 54-62.

Lohumi, S., Lee, S., Lee, H., and Cho, B. K. (2015). A review of vibrational spectroscopic techniques for the detection of food authenticity and adulteration. Trends in Food Science and Technology, 46(1), 85-98.

Lucas, J. A. (2011). Advances in plant disease and pest management. The Journal of Agricultural Science, 149(S1), 91-114.

Mahlein, A. K. (2016). Plant disease detection by imaging sensors-parallels and specific demands for precision agriculture and plant phenotyping. Plant Disease, 100(2), 241-251.

Martin, F. L., German, M. J., Wit, E., Fearn, T., Ragavan, N., and Pollock, H. M. (2007). Identifying variables responsible for clustering in discriminant analysis of data from infrared microspectroscopy of a biological sample. Journal of Computational biology, 14(9), 1176-1184.

Martin, F. L., Kelly, J. G., Llabjani, V., Martin-Hirsch, P. L., Patel, I. I., Trevisan, J., ... Walsh, M. J. (2010). Distinguishing cell types or populations based on the computational analysis of their infrared spectra. Nature Protocols, 5(11), 1748-1760.

Martinelli, F., Scalenghe, R., Davino, S., Panno, S., Scuderi, G., Ruisi, P., ... Davis, C. E. (2015). Advanced methods of plant disease detection. A review. Agronomy for Sustainable Development, 35(1), 1-25.

McCann, M. C., Hammouri, M., Wilson, R., Belton, P., and Roberts, K. (1992). Fourier transform infrared microspectroscopy is a new way to look at plant cell walls. Plant Physiology, 100(4), 1940-1947.

Moros, J., Garrigues, S., and de la Guardia, M. (2010). Vibrational spectroscopy provides a green tool for multi-component analysis. TrAC Trends in Analytical Chemistry, 29(7), 578-591. 
Movasaghi, Z., Rehman, S., and Rehman, I. U. (2007). Raman spectroscopy of biological tissues. Applied Spectroscopy Reviews, 42(5), 493-541.

Movasaghi, Z., Rehman, S., and ur Rehman, D. I. (2008). Fourier transform infrared (FTIR) spectroscopy of biological tissues. Applied Spectroscopy Reviews, 43(2), 134179.

Nutter Jr, F. W., van Rij, N., Eggenberger, S. K., and Holah, N. (2010). Spatial and temporal dynamics of plant pathogens. In Precision Crop Protection-the Challenge and Use of Heterogeneity (pp. 27-50). Springer Netherlands.

Oerke, E. C. (2006). Crop losses to pests. The Journal of Agricultural Science, 144(01), 31-43.

Oerke, E. C., and Dehne, H. W. (2004). Safeguarding production-losses in major crops and the role of crop protection. Crop protection, 23(4), 275-285.

Ord, J., Butler, H. J., McAinsh, M. R., and Martin, F. L. (2016). Spectrochemical analysis of sycamore (Acer pseudoplatanus) leaves for environmental health monitoring. Analyst, 141(10), 2896-2903.

Patel, S. A., Currie, F., Thakker, N., and Goodacre, R. (2008). Spatial metabolic fingerprinting using FT-IR spectroscopy: investigating abiotic stresses on Micrasterias hardyi. Analyst, 133(12), 1707-1713.

Quaroni, L., and Zlateva, T. (2011). Infrared spectromicroscopy of biochemistry in functional single cells. Analyst, 136(16), 3219-3232.

Radu, A. I., Ryabchykov, O., Bocklitz, T. W., Huebner, U., Weber, K., Cialla-May, D., and Popp, J. (2016). Toward food analytics: fast estimation of lycopene and $\beta$-carotene content in tomatoes based on surface enhanced Raman spectroscopy (SERS). Analyst, 141(14), 4447-4455.

Ramirez, F. J., Luque, P., Heredia, A., and Bukovac, M. J. (1992). Fourier transform IR study of enzymatically isolated tomato fruit cuticular membrane. Biopolymers, 32(11), 1425-1429.

Ray, D. K., Mueller, N. D., West, P. C., and Foley, J. A. (2013). Yield trends are insufficient to double global crop production by 2050. PloS one, 8(6), e66428.

Ribeiro da Luz, B. (2006). Attenuated total reflectance spectroscopy of plant leaves: a tool for ecological and botanical studies. New Phytologist, 172(2), 305-318.

Rodriguez-Saona, L. E., and Allendorf, M. E. (2011). Use of FTIR for rapid authentication and detection of adulteration of food. Annual Review of Food Science and Technology, 2, 467-483.

Rösch, P., Kiefer, W., and Popp, J. (2002). Chemotaxonomy of mints of genus Mentha by applying Raman spectroscopy. Biopolymers, 67(4 5), 358-361. 
Sankaran, S., Mishra, A., Ehsani, R., and Davis, C. (2010). A review of advanced techniques for detecting plant diseases. Computers and Electronics in Agriculture, 72(1), $1-13$.

Savary, S., Ficke, A., Aubertot, J. N., and Hollier, C. (2012). Crop losses due to diseases and their implications for global food production losses and food security. Food Security, $1-19$.

Schulz, H., and Baranska, M. (2007). Identification and quantification of valuable plant substances by IR and Raman spectroscopy. Vibrational Spectroscopy, 43(1), 13-25.

Ścibisz, I., Reich, M., Bureau, S., Gouble, B., Causse, M., Bertrand, D., and Renard, C. M. (2011). Mid-infrared spectroscopy as a tool for rapid determination of internal quality parameters in tomato. Food Chemistry, 125(4), 1390-1397.

Smith, B. C. (2011). Fundamentals of Fourier transform infrared spectroscopy. CRC press.

Smith, E., and Dent, G. (2013). Modern Raman spectroscopy: a practical approach. John Wiley and Sons.

Stables, R., Clemens, G., Butler, H. J., Ashton, K. M., Brodbelt, A., Dawson, T. P., ... Baker, M. J. (2017). Feature driven classification of Raman spectra for real-time spectral brain tumour diagnosis using sound. Analyst, 142(1), 98-109.

Strange, R. N., and Scott, P. R. (2005). Plant disease: a threat to global food security. Annual Review of Phytopathology, 43.

Stuart, B. (2004). Infrared Spectroscopy: Fundamental and Applications.

Stewart, D., Yahiaoui, N., McDougall, G. J., Myton, K., Marque, C., Boudet, A. M., and Haigh, J. (1997). Fourier-transform infrared and Raman spectroscopic evidence for the incorporation of cinnamaldehydes into the lignin of transgenic tobacco (Nicotiana tabacum L.) plants with reduced expression of cinnamyl alcohol dehydrogenase. Planta, 201(3), 311-318.

Suzuki, N., Rivero, R. M., Shulaev, V., Blumwald, E., and Mittler, R. (2014). Abiotic and biotic stress combinations. New Phytologist, 203(1), 32-43.

Talari, A. C. S., Martinez, M. A. G., Movasaghi, Z., Rehman, S., and Rehman, I. U. (2016). Advances in Fourier transform infrared (FTIR) spectroscopy of biological tissues. Applied Spectroscopy Reviews, 1-51.

Talari, A. C. S., Movasaghi, Z., Rehman, S., and Rehman, I. U. (2015). Raman spectroscopy of biological tissues. Applied Spectroscopy Reviews, 50(1), 46-111.

Thygesen, L. G., Løkke, M. M., Micklander, E., and Engelsen, S. B. (2003). Vibrational microspectroscopy of food. Raman vs. FT-IR. Trends in Food Science and Technology, 14(1), 50-57.

Trebolazabala, J., Maguregui, M., Morillas, H., de Diego, A., and Madariaga, J. M. (2013). Use of portable devices and confocal Raman spectrometers at different 
wavelength to obtain the spectral information of the main organic components in tomato (Solanum lycopersicum) fruits. Spectrochimica Acta Part A: Molecular and Biomolecular Spectroscopy, 105, 391-399.

Trevisan, J., Angelov, P. P., Carmichael, P. L., Scott, A. D., and Martin, F. L. (2012). Extracting biological information with computational analysis of Fourier-transform infrared (FTIR) biospectroscopy datasets: current practices to future perspectives. Analyst, 137(14), 3202-3215.

Wei, Z. L., Dong, L., and Tian, Z. H. (2009). Fourier transform infrared spectrometry study on early stage of cadmium stress in clover leaves. Pakistan Journal of Botany, 41(4), 1743-1750.

Wesełucha-Birczyńska, A., Łabanowska, M., Kurdziel, M., and Filek, M. (2012). Resonance Raman and EPR spectroscopy studies of untreated spring wheat leaves. Vibrational Spectroscopy, 60, 113-117.

White, K. E., Reeves, J. B., and Coale, F. J. (2016). Cell wall compositional changes during incubation of plant roots measured by mid-infrared diffuse reflectance spectroscopy and fiber analysis. Geoderma, 264, 205-213.

Wilson, R. H., Smith, A. C., Kačuráková, M., Saunders, P. K., Wellner, N., and Waldron, K. W. (2000). The mechanical properties and molecular dynamics of plant cell wall polysaccharides studied by Fourier-transform infrared spectroscopy. Plant Physiology, 124(1), 397-406.

Yang, J., and Yen, H. E. (2002). Early salt stress effects on the changes in chemical composition in leaves of ice plant and Arabidopsis. A Fourier transform infrared spectroscopy study. Plant Physiology, 130(2), 1032-1042.

Zhang, H., Chen, N., Liu, S., Li, T., Xu, W., and Chen, Z. (2017). Surface-enhanced Raman scattering spectra revealing the inter-cultivar differences for Chinese ornamental Flos Chrysanthemum: a new promising method for plant taxonomy. Plant Methods, 13(1), 92.

Zimmermann, B., and Kohler, A. (2014). Infrared spectroscopy of pollen identifies plant species and genus as well as environmental conditions. Plos One, 9(4), e95417.

Zimmermann, B., Bağcıoğlu, M., Sandt, C., and Kohler, A. (2015). Vibrational microspectroscopy enables chemical characterization of single pollen grains as well as comparative analysis of plant species based on pollen ultrastructure. Planta, 242(5), 1237-1250.

Zohdi, V., Whelan, D. R., Wood, B. R., Pearson, J. T., Bambery, K. R., and Black, M. J. (2015). Importance of tissue preparation methods in FTIR micro-spectroscopical analysis of biological tissues:'Traps for new users'. PLoS One, 10(2), e0116491. 